\title{
As contribuições de Heider e Lévi-Strauss para teoria da grupabilidade: uma reflexão à luz da estrutura das relações de redes de empresas
}

\author{
Nivaldo Oliveira ${ }^{1}$; Mardem Leandro Silva ${ }^{2}$; Cleber Carvalho de Castro ${ }^{3}$
}

Resumo: O propósito deste ensaio teórico é a realização de um debate sobre grupabilidade, que historicamente marcou e ainda continua a influenciar as discussões dentro da teoria de redes. Para tal, serão reverberadas as teorias dos autores Heider e Levi-Strauss, considerados relevante para essa discussão, na tentativa de evidenciar as especificidades, as contribuições e os avanços alcançados nesse campo do saber. Ao se traduzir as teorias abordadas neste trabalho, podemos intuir que a cooperação interorganizacional pode proporcionar inúmeros benefícios, uma vez que atende as necessidades das empresas que seriam difíceis de serem alcançadas quando atuam isoladamente.

Palavras-chave: Redes de empresa; Cooperação interorganizacional; Redes sociais; Grupabilidade; Átomo do parentesco; Atribuição causal e equilíbrio cognitivo.

\section{The Contributions of Lévi-Strauss and Heider to the Theory of Groupality: A Reflection in Light from the Structure Relations of Company Networks}

\begin{abstract}
The purpose of this theoretical paper is to conduct a debate on groupality, which historically marked and continues to influence discussions within the network theory. This will be reverberated theories of Heider and Levi-Strauss, considered relevant to this discussion, in an attempt to highlight the specifics, contributions and achievements in this field of knowledge. When translating the theories discussed in this work, we can intuit that interorganizational cooperation can provide numerous benefits, since it meets the needs of businesses that would be difficult to be achieved when they work separately.
\end{abstract}

Keywords: Network company; interorganizational cooperation, social networks, Groupality; Atom of kinship; Causal attribution and cognitive balance.

\footnotetext{
${ }^{1}$ Mestrando em Administração pela Universidade Federal de Lavras, Especialista em Gestão do Conhecimento e Tecnologia da Informação e graduação em Biblioteconomia pelo Centro Universitário de Formiga - UNIFOR/MG, Bibliotecário da Universidade Federal de Lavras, MG. E-mail: nivaldo@ biblioteca.ufla.br

${ }^{2}$ Mestrando em Psicologia pela Universidade Federal de São João Del Rei e graduado em Psicologia pela Pontifícia Universidade Católica de Minas Gerais em Arcos. E-mail: mardemls@yahoo.com.br

${ }^{3}$ Doutorado em Agronegócios pela Universidade Federal do Rio Grande do Sul (2006), mestrado em Administração pela Universidade Federal do Rio Grande do Sul (1998) e graduação em Administração pela Universidade Federal de Lavras (1995). Atualmente é professor Adjunto da Universidade Federal de Lavras. E-mail: clebercastro@dae.ufla.br
}

\section{Introdução}

Devido ao aumento da competitividade, atuar isoladamente tornou-se complexo e desfavorável. A lógica predominante das redes está vinculada a possibilidade de ganhos para todos os integrantes de um negócio, pois, o foco das decisões dos envolvidos passa da posição individual para coletiva, na busca de inovações, avanços e aceleração da produtividade e inserção no mercado.

O termo rede por si é uma noção abstrata que se refere a um conjunto de nós conectados por relacionamentos. Várias empresas, organizações ou mesmo pessoas aglomeram-se de determinada 
forma para obter determinados resultados e algum tipo de contato que irá gerar possibilidades não adquiridas quando se trabalha isoladamente.

Nesse sentido, o propósito deste ensaio teórico é a realização de um debate sobre grupabilidade e as relações interpessoais, que historicamente marcou e influencia as discussões dentro da teoria das redes. Para tal, são explanadas as teorias de Heider e Levi-Strauss, considerando sua importância e as suas contribuições para os avanços nesse campo do saber.

Iniciando por uma revisão bibliográfica sobre grupabilidade, segue o texto através da teoria da atribuição causal ao equilíbrio cognitivo de Heider e da teoria do átomo do parentesco e do estruturalismo antropológico de Lévi-Strauss. Em seguida, foi traçado a convergência entre os trabalhos e os pensamentos de Heider e Levi-Strauss no âmbito da teoria de redes de relacionamento. Por fim, têm-se as considerações finais do estudo.

\section{Teoria da grupabilidade}

Um grupo consiste de duas ou mais pessoas que interagem e compartilham objetivos comuns, possuem uma relação estável, são mais ou menos independentes e percebem que fazem, de fato, parte do grupo (PAULUS, 1989).

A teoria da grupabilidade mostra que, se os elementos A e B, bem como os elementos A e C, estejam ligados de forma positiva, os elementos B e C provavelmente também estarão. A consonância entre elementos de uma tríade pode igualmente existir através de uma relação positiva entre dois deles, tendo cada uma, relação negativa com o terceiro. Nesse sentido poderá tratar-se de uma pessoa com duas opiniões e da relação entre elas. A grupabilidade existe quando há vários blocos, de tal maneira que as relações internas de um bloco, quando identificadas, são todas positivas ou neutras e as relações externas, são todas negativas ou neutras (LEMIEUX e OUIMET, 2008).

Por vezes, as relações entre as pessoas, ou ainda entre as proposições, podem ser neutras. Estas relações tem a vantagem de não serem nem positivas nem negativas, o que facilita o princípio de grupabilidade. Ao transgredir este princípio, surgem tensões que também tem a tendência de arrastar a situação em direção a grupabilidade (LEMIEUX e OUIMET, 2008).

Buscando clarear o entendimento das relações interpessoais, dentro de análise de redes sociais, este debate teórico aborda como base de sua fundamentação, o pensamento de Heider e Levi-Strauss que tiveram grande significância para o estudo da teoria da grupabilidade e a estrutura das redes sociais.

Id en line Revista de Psicologia. Ano 8, No. 22, Fevereiro/2014 - ISSN 1981-1179.

Edição eletrônica em http://idonline.emnuvens.com.br/id 


\section{Da teoria da atribuição causal ao equilíbrio cognitivo de Fritz Heider}

A partir do momento em que o social torna-se uma categoria explicativa para o comportamento, configura-se se como um objeto da psicologia social, que a um só tempo consegue perceber a conexão intrínseca entre o individual e o social, amenizando a figura do indivíduo psicológico como categoria única para explicação dos processos intersubjetivos. Tem-se neste momento outra medida de significação, pois estes processos são passíveis de serem interpretados por uma metodologia que os transforma em mecanismos sociais. O que proporciona a conclusão de que a explicação dos mecanismos sociais não pode ser reduzida a uma abordagem psicológica somente, ou que, no mínimo, é possível equacionar outras categorias explicativas, com noções causais descentralizadas ou compostas. Isso pelo fato de que a interdependência da relação indivíduosociedade tem se tornado uma evidência que compõe o cerne da investigação da psicologia social. Assim, parte de uma noção de causa que é ao mesmo tempo estranha e previsível, uma noção atributiva, sobretudo, se pensada como recurso para poder explicar a interferência dos outros no comportamento do indivíduo. Partindo desta problemática, Fritz Heider elabora os princípios de sua teoria da atribuição.

O psicólogo vienense Fritz Heider (1896-1988) foi reconhecido como um importante teórico da psicologia social por desenvolver uma teoria a respeito das relações interpessoais e se dizia interessado em investigar a relação dos fenômenos tidos como "superficiais", em contraposição ao que poderia ser considerado como fenômenos "profundos", similar aos trabalhos de Granovetter (1973), quando explora a força dos laços fracos e fortes. Estas relações humanas, "óbvias" e intuitivamente entendidas, podem ser tão provocantes e psicologicamente significantes quanto os fenômenos mais profundos e mais estranhos (HEIDER, 1970). Esta diferenciação não era sem razão, haja vista as explicações em voga na área social estarem estruturadas ao redor das referências feitas à Freud e outros autores da psicanálise que interpretavam a dinâmica social a partir de uma perspectiva subjetivista que postulava como padrão os fenômenos inconscientes, tidos como fenômenos profundos.

Heider partiu do princípio de que as atitudes que uma pessoa poderia desenvolver em relação às demais pessoas seriam agenciadas pelo princípio de atribuição causal, que interferiria diretamente em sua disposição cognitiva. A teoria da atribuição causal de Heider (1970) ampara-se no senso de que os indivíduos utilizam os artifícios e acontecimentos hodiernos no seu universo para construírem padrões comportamentais causais, indutivos ou dedutivos, estabelecendo relacionamentos entre causas e efeitos.

Id en line Revista de Psicologia. Ano 8, No. 22, Fevereiro/2014 - ISSN 1981-1179. Edição eletrônica em http://idonline.emnuvens.com.br/id 
Em sua investigação, compartilhou dos importantes avanços da psicologia social, sobretudo da teoria da atribuição, que afirmava que as causas dos fenômenos seriam explicadas por atribuição. Heider defende a sensatez no uso das ideias mais gerais, a respeito do comportamento humano (HEIDER, 1970, pp. 18). Apesar de não perder de vista toda a dimensão do trabalho científico e submeter estas mesmas ideias a uma rigorosa sistematização, o intuito era de formular uma teoria que possa ser responsável pelas relações interpessoais, o que se aplica às redes de empresas.

O uso do princípio de atribuição, demonstrando que além de tantas outras condições, os fatores pessoais influenciariam na percepção das relações interpessoais. Heider (1970) atribui à psicologia do senso comum o reconhecimento de conjuntos de condições em jogo na percepção dos fenômenos referentes ao objeto ou à mediação. Desta forma, a atribuição causal seria relativa a um modo "intuitivo" das percepções causais, ou seja, determinado comportamento teria sua causa atribuída conforme a disposição cognitiva daquele que o perceberia, e esta teoria receberia o nome de atribuição causal da conduta social.

A contribuição de Heider para esta teoria preexistente se refere à identificação do que ele considerava como sendo alguns invariantes causais. A identificação dos invariantes ou das constâncias é o que de fato permite certo controle e previsão em determinado ambiente. Assim, determinado comportamento poderia ser descrito e explicado a partir desta noção de causalidade, seja ela interna (disposicional) ou externa (situacional). Para Heider (1970), o indivíduo está constantemente atribuindo o que ocorre ao seu meio a fatores situacionais bem específicos. As consequências diretas destas atribuições são percebidas no plano cognitivo, pois uma determinada explicação causal vai influenciar em uma resposta específica, o que implica num comportamento diferente para uma concepção de causa diferente. Uma percepção causal gera uma cognição, que permite uma explicação causal das ações, que por sua vez influencia na resposta, sendo também causa de uma conduta específica, que deste modo participa da construção do significado da mesma.

O que está em jogo na predição e no controle das ações é o modo viciado como o indivíduo percebe o que ocorre à sua volta, atribuindo causa aos eventos e como a mesma atribuição afetaria o modo por meio do qual o indivíduo se relacionaria com o seu meio social. Desta forma, segundo Ferreira, Heider foi em direção de realizar um trabalho de sistematização dos processos atribuitivos, "[...] ao lançar o argumento de que os indivíduos associam as ações das pessoas a motivos e disposições internas, em função de perceberem uma justaposição ou gestalt entre o modo pelo qual as pessoas se comportam e a natureza de suas qualidades pessoais" (FERREIRA, 2010, pp. 78).

Foi em sua "Psicologia dos Processos Interpessoais" de 1958, que Heider conferiu consistência maior ao argumento da atribuição causal. Entretanto, ainda trabalhou no desenvolvimento de uma teoria do equilíbrio cognitivo, que propunha que as pessoas disporiam de uma tendência a manter seus sentimentos e cognições comedidas, ou seja, de manter coerentes as cognições e os 
sentimentos sobre uma mesma pessoa ou objeto, de forma a alcançar e fazer permanecer uma situação equilibrada. Desfazendo esta situação estável sobreveria um estado de tensão que seria imediatamente percebido e sentido como aversivo, gerando uma tentativa de reposição da situação de equilíbrio cognitivo, a partir da mudança de alguns dos elementos em jogo na situação.

Assim, Heider (1970) propõe que os indivíduos estão constantemente construindo e tentando manter coeso um sistema de relações que seja equilibrado, o que implica em ligações de ao menos três elementos cognitivos: os próprios do indivíduo, do outro e dos referentes aos acontecimentos ou aos objetos. É possível distinguir dois tipos de relação no sistema, a primeira é referente às unidades, diz respeito às cognições de dois ou mais elementos fazendo parte da mesma funcionalidade, a segunda é referente às relações de sentimento e diz respeito a cognições afetivas, que tornam possíveis as avaliações qualitativas.

A partir desta exposição, Heider conclui que existiria equilíbrio cognitivo nas relações se elas partissem da ligação entre as cognições do próprio sujeito e as relativas ao outro. Por fim, estar vinculado ou envolvido com uma pessoa é, em si mesmo, uma configuração, que tem de ser mantida em equilíbrio cognitivo. Se existirem mudanças na percepção, isso implica haver alteração em todo o sistema, transformando o sentimento relativo a essa pessoa. Isto implica que a totalidade do sistema tem de ser reequilibrada.

Ao analisar a teoria Heider (1970), na busca por uma mediação entre a teoria de redes, podemos compreender com mais clareza a forma como os clusters surgem e seu caráter de interrelação. Os aglomerados são caracterizados como redes de colaboração e de concentrações de cooperação e de competição que oferecem oportunidades e estimulam o desenvolvimento econômico (Porter, 1998). Um cluster industrial é definido como um grupo cooperativo geográfico que inclui fornecedores, consumidores, periféricos indústrias, governos e instituições de apoio, como as universidades, buscando um equilíbrio e harmonia para se manterem e obterem lucros da rede de relacionamento em que está inserida.

\section{O átomo do parentesco e o estruturalismo de Claude Lévi-Strauss}

O trabalho de Claude Lévi-Strauss (1980) se inscreve de tal modo na perspectiva do pensamento atual que se torna indispensável para a reflexão de uma noção mais abrangente de grupabilidade. Isso pelo fato de sua proposta metodológica conseguir tornar claro o modo por meio do qual se dão as relações dentro de determinado grupo.

Segundo Ávila (2000) somos individualmente, em termos, como uma página de um livro, autônoma, porém, somente lhe cabe significado por ser parte de um todo, de uma história que nos 
http://idonline.emnuvens.com.br/id ISSN on-line: 1981-1179

transcende, a escritura múltipla que nos intercala, nos combina, nos põe em seqüência e desenvolve a história.

Para o estruturalismo de Lévi-Strauss, um fato isolado, enquanto tal, jamais possui significado (CHAUÍ, 1980), o que equivale dizer que um significado só tem sentido na perspectiva de um corpo estrutural, a partir do qual torna possível uma relação de referências.

Adotando esta analogia em estruturas de redes interorganizacionais sugere que as organizações não sobrevivem isoladamente. Organizações instaladas em localidades onde se pode identificar um alto desempenho industrial tendem a oferecer mais oportunidades de inovação a regiões com empresas instalas de formas dispersas. Consequentemente, com esta aproximação beneficiam-se, por exemplo, através da redução dos custos transação.

A perspectiva estruturalista, no que tange a reflexão sobre os grupos, centraliza o debate na figura da relação, que é partidária da existência de regras estruturantes da mente e das diversas culturas humanas, e ainda afirma o duplo papel que as regras assumem: o de construir pares de oposição e de organização do sentido.

O conhecido como método estruturalista de análise das relações de parentesco, sugere a teoria da aliança, também chamada teoria da troca generalizada. Conforme San Roman e Echavarría (1994) a teoria da aliança tem orientado grande parte dos trabalhos da antropologia social, especialmente até a década de 1980, e teve ressonância em outros campos de análise, incluindo a psicanálise, a filosofia e a política.

Segundo Sarti (2009) o símbolo orquestrado da teoria de Lévi-Strauss, no que se tange à família e ao parentesco, houve seu estabelecimento no sentido de proporcionar em definitivo a antropologia cultural. Seu entendimento altera substancialmente a ideia que identifica a família como a unidade biológica - pai, mãe e filhos. Para Lévi-Strauss (1980) a família, em seu fundamento natural (família consangüínea), precisa se desfazer para que exista a sociedade, conforme figura 1, ao mesmo tempo em que a sociedade (grupos dispostos a reconhecer seus limites e a se abrir ao outro) é condição da existência da família (SARTI, 2009). 


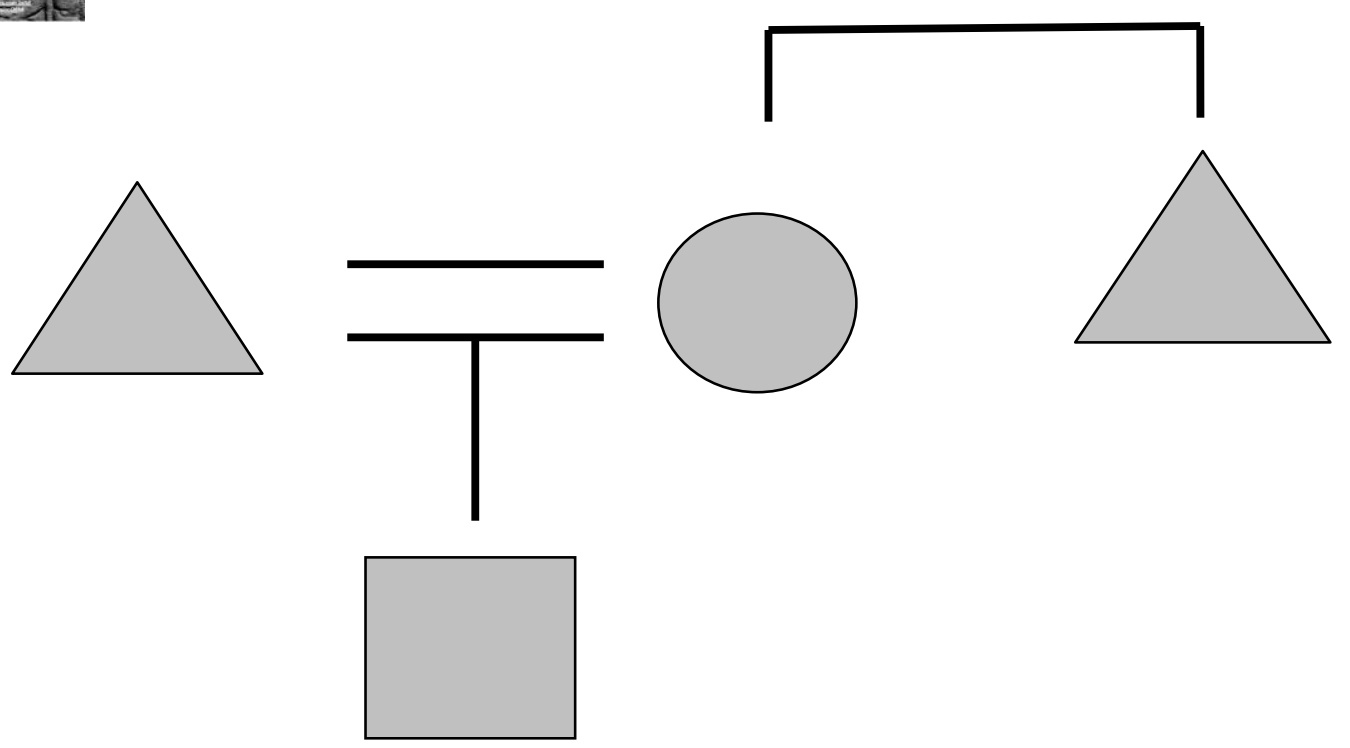

Figura 1 - RepresentaÇÃo Do Átomo De Parentesco

Fonte: Adaptado de Pellón (2010)

Nesta representação gráfica do átomo do parentesco, como proposto por Claude Lévi-Strauss, o sexo masculino é simbolizado por um triângulo, e o feminino por um círculo. A prole, qualquer gênero, é representada com um quadrado. Segundo Sarti (2009) a unidade elementar que envolve as relações que constituem os sistemas de parentesco corresponde, na formulação de Lévi-Strauss, não a um sistema triangular de relações, mas quadrangular: entre marido e mulher, pai e filho, irmão e irmã e tio materno e sobrinho. São quatro pares de relações (e não apenas as três: marido-mulher, pai-filho, irmão-irmã) que constituem o "átomo do parentesco", o que pressupõe a existência prévia de dois grupos, um que recebeu e outro que deu a mulher em casamento.

\section{Convergências entre as teorias da estrutura da grupabilidade}

Para Lévi-Strauss (1980) o fenômeno da troca se constituiria como sendo o objeto que seu método estruturalista analisaria. Tal como afirma Simanke (2002) em seu estudo sobre as influências da antropologia estruturalista no pensamento de Jacques Lacan, no que diz respeito aos usos de categorias sociais para justificar categorias lógicas, ou seja, como o social e sua estrutura estariam no princípio de constituição dos sujeitos.

Simanke afirma que "[...] se o estruturalismo concebe a estrutura social fundamentalmente como um sistema de trocas (de bens, de palavras), é porque trata-se aí de uma operação que combina entre si os elementos, doravante simbólicos, que compõem essa mesma estrutura e, com isso, é 
possível deslocar a ênfase do objeto trocado para a própria troca, o que significa preterir o que resta de empirismo em antropologia em benefício da abordagem formal” (SIMANKE, 2002, pp. 393).

Esta abordagem formal é o que estaria na base da investigação estrutural, na forma do procedimento invariável no qual os elementos se articulariam. Uma premissa geral do pensamento de Lévi-Strauss (1980) é que o social se disporia como condição necessária para a existência da família. Evidentemente, trata-se da família humana, sobretudo como objeto de investigação do olhar antropológico, enviesado pelo procedimento etnográfico e pelo método estruturalista de inspiração linguística. De posse destes recursos Lévi-Strauss (1980) percebe que muito dos rituais, até então sem conexão lógica, passa a ter ligações na medida em que são pensados como elementos dentro de uma ampla estrutura, tal como ocorre com os fonemas (unidades de som) dentro da estrutura da linguagem. Assim, as relações de parentesco são organizadas no intuito de favorecer a comunicação entre os grupos familiares distintos.

Entretanto, a relação entre a família e o social é inteiramente sistêmica, o que significa que um termo age sobre o outro de forma recursiva, ou seja, se o social é condição para o familiar é porque o familiar recursivamente gera condições para o social. De tal modo, na mesma medida em que o social se dispõe como condição necessária para a emergência da família humana, a família se dispõe como fundamento do social. Na perspectiva de Lévi-Strauss, Cynthia Andersen Sarti sustenta que"[... a família funda o social, mas não nos termos funcionais da biologia humana. Ao contrário, na existência da família, concebida como aliança entre grupos, está a possibilidade do ser humano se fazer social, comunicando-se e, assim, romper com o que o autor define como o isolamento a que nos condena a consangüinidade" (SARTI, 2009).

Esta condenação estaria na raiz da relação grupal, no sentido de que movimentaria todo um regime de trocas e comunicação entre as pessoas. Lévi-Strauss (1980) postula a proibição do incesto como regra geral, na mesma medida em que verifica que a linguagem ocupa esta mesma posição. Em outras palavras, a lei do incesto é homóloga às regras da linguagem, ambas operariam restrições necessárias para que houvesse a possibilidade de se fazer distinções entre os grupos e desta forma propiciariam condições de relações entre eles. Assim, num primeiro plano, a família se configuraria como um sistema de comunicação, em que a reciprocidade e a troca seriam sua estrutura fundamental, tal como observa Sarti "O objetivo das relações de parentesco, como de qualquer sistema social, é instituir a comunicação, na qual o sujeito só se define em relação a um outro. Os elementos não são pensados por suas propriedades intrínsecas (não interessa a família individualizada), mas pelas relações nas quais estão situados. Nesse ponto, é clara a analogia entre a antropologia e a linguística. Ambas operam a partir da ideia da troca como uma estrutura fundante. As relações de parentesco são, assim, uma linguagem, segundo Lévi-Strauss" (SARTI, 2009). 
Desta forma, pensar a grupabilidade na perspectiva estruturalista dos átomos de parentesco de Lévi-Strauss significaria pensar a propriedade do grupo, a qualidade do que faria uma aglomeração funcionar como tal. Isso significa dizer que nem todo aglomerado pode responder pela condição de um grupo, ou seja, a grupabilidade já seria uma forma de se pensar sua identidade, o que o caracterizaria ao ponto de poder ser reconhecido, teorizado e fornecer condições para a prática. Assim, a premissa geral de Lévi-Strauss garante uma abordagem mais ampla da noção de grupabilidade por tornar transparente sua condição de possibilidade, a saber, a comunicação, as suas conexões.

Entretanto, menos do que se comunicar, os grupos precisam ter no interior de sua constituição a relação comunicativa de seus elementos. Evidentemente, isso se dá pelo recurso do que possa organizar esta comunicação, esta relação. Para Lévi-Strauss (1980) duas regras são fundamentais: a proibição do incesto (aqui tomada somente na dimensão de lei) e a linguagem. Estas duas regras para funcionarem bem, precisam operar de modo inconsciente, no limite de serem confundidas como condições da própria natureza. Assim, leis regulariam o funcionamento do grupo, por um lado mantendo a comunicação e a troca daquilo que a tradição tem por bem de ser passado e por outro dispondo as pessoas de trocarem de grupos. Isso acontece por que, as mulheres não poderiam se relacionar com os membros do próprio grupo, da própria família e assim deveriam buscar pretendentes fora do grupo familiar.

Desta forma, a condição de bom funcionamento é que a regra opere silenciosamente, de modo subterrâneo, inconsciente. O que não seria impedimento para que fosse atribuído toda sorte de causas para a propriedade destas relações grupais. Em outros termos, o homem dito primitivo explicaria a dinâmica das suas relações de parentesco pelo recurso dos mitos, lendas e construções imagináriosimbólicas, deixando antever a relação supersticiosa com a estrutura do que o determinava.

Saindo do cenário dito primitivo e passando para a atualidade dos processos grupais, LéviStrauss (1980) permanece como um teórico preciso das relações grupais, por oferecer recursos para ampla compreensão da dinâmica entre os grupos e do grupo consigo mesmo, pensando-os a partir da relação não hierárquica de seus elementos e do ponto vazio da estrutura, ponto estes que é o pivô do movimento estrutural dos elementos. Neste vazio residiria o ponto de convergência entre a natureza e a humanidade. Segundo Franca D’agostine este vazio é previsto pela teoria estruturalista para a qual a estrutura é determinada por uma ausência, um elemento que falta, “as estruturas não são estáticas, são dotadas de um certo movimento, dado pelo deslocar-se de um ou mais termos de uma colocação a uma outra. Isso gera uma reorganização [permanente] da estrutura, e a possibilidade de obtê-la é dada pelo fato de que em cada sistema de relações estruturais existe uma 'articulação sem objeto', um 'compartimento vazio'.” (D’AGOSTINE, 2002, pp. 542).

Estas articulações sem objeto são próprias do humano e se configuram como espaço de simbolização, no sentido de unir significações ou cognições aparentemente díspares. É no espaço do 
que falta para ser plenamente significado que surge a possibilidade de se trabalhar com outras cognições, ou seja, é justamente pelo fato de haver um ponto cego na estrutura que as atribuições causais, como propõe Heider, se tornam um processo cognitivo legítimo, pois, em tese, o vazio da estrutura se estenderia a todos os objetos, no sentido de que, no limite, todos representariam, ao fim e ao cabo, uma estrutura.

Assim, ao menos dois pontos da proposta estruturalista lançam nova luz a uma problematização da teoria da grupabilidade: a de que um grupo se define pela dinâmica não hierarquizada dos elementos (a hierarquia seria uma sobreposição destes elementos) e que o centro ausente, ou o vazio fundamental da estrutura, seria responsável pelo movimento da mesma. Nos dois pontos pode ser estabelecida uma relação com a proposta de Heider sobre a atribuição causal. No primeiro por pressupor continuidade, estabilidade e relação ordenada dos elementos o que para Heider significa que "frequentemente essa ordenação e essa classificação podem ser consideradas como um processo de atribuição" (HEIDER, 1970, p. 330), sobretudo se o referente for a organização do ambiente subjetivo. E no segundo, pelo centro ausente, no qual se vê estabelecido o lugar da lei como resposta ao que falta a significar, ou seja, o ponto de passagem da natureza para a cultura, que pela articulação com Heider percebe-se que algo é posto no lugar do vazio e que este algo opera como causa.

A lei como causa faz movimentar a estrutura, como bem ilustra a restrição universal do incesto, descrita por Lévi-Strauss (1980). Sendo representado o vazio, intuitivamente ele deixa de existir, mas, no entanto, não deixa de causar. Assim os principais processos da subjetividade (ambiente psíquico) precisam ser representados para que com eles se estabeleça uma relação cognitiva. Para Heider (1970, p. 329) "os principais aspectos do ambiente são dados em representação", se o sujeito se encontra em dada situação e algo inesperado ocorre, este acontecimento precisa ser ajustado à situação como um todo. Heider exemplifica que "[...] nosso ambiente subjetivo contém o eu e outra pessoa, e ocorre um novo acontecimento: uma das pessoas será considerada responsável por este último. Vale dizer, interpretamos os acontecimentos como causados por partes específicas do ambiente relativamente estável" (HEIDER, 1970, p. 30).

Esta descrição da atribuição se ajusta à noção de grupabilidade por manter presente o trabalho de significação sempre em jogo na manutenção do grupo, pois para Heider os indivíduos estariam irremissivelmente construindo e tentando manter em equilíbrio seus sistemas de relações.

Podemos perceber que as perspectivas adotadas pela psicologia social, defendidas Heider e Lévi-Strauss, nos direciona para as características globalizantes que tem se introduzido nas relações organizacionais, bem como, as inovações tecnológicas, o surgimento de novos conceitos e novas práticas de gestão, onde cada empresa por meio das pessoas e dos grupos que as compõem interage com outros membros através de suas ações políticas, econômicas, culturais e/ou sociais. 


\section{Aspectos conceituais de redes de relacionamento}

A competitividade cada vez mais acirrada, em função do processo de internacionalização e globalização, contribui para determinar a forma predominante da estratégia da empresa. Atualmente as redes de empresas e as relações de confiança e cooperação ganharam grande destaque. Sua principal característica é estabelecida a partir das relações que se formam entre seus atores, se agrupando e se aglomerando. Essa denominação permite estabelecer importância significativa ao capital social presente na estrutura de rede.

Para compreensão das redes de relacionamento, Granovetter (1973) sugere a análise de redes sociais como um instrumento de ligação entre micro e macro níveis de teoria sociológica. Nas suas argumentações sobre as conexões dos atores em rede, foram mencionados alguns fatores para explicar o modo como os recursos disponíveis, por meio das redes sociais, condicionam os resultados das ações dos indivíduos como os seus laços, suas interações e relações sociais. Há uma busca por compreender como esses conceitos relacionam-se com a produção de capital social e como pode ser verificado em diversos grupos, na busca pela construção de confiança das relações cooperativas que no mercado global altamente competitivo tem ganhado grande importância.

O cerne de toda e qualquer relação entre empresas são as pessoas que estão por traz das parcerias. Segundo Brusco (1990) a cooperação deve ser estimulada por duas condições, mais exatamente a difusão da informação e a rica rede de relacionamentos que cada um de nós possui com outras pessoas.

Contratos não-escritos ganharam, portanto, valor e têm sido amplamente usados. Sua regulamentação é gerenciada pela comunidade de indivíduos competentes que têm consciência do que está acontecendo ao seu redor. No que diz respeito à construção de enlaces, Granovetter (1973) salienta que a força e a intensidade deles podem variar entre fortes e fracos. $\mathrm{O}$ autor demonstra que a força dos laços entre os indivíduos denomina o grau de sobreposição dos mesmos nas redes. Quanto mais forte os laços de relacionamento e interação interpessoal entre agentes, mais consistente é a base de confiança, comprometimento e a responsabilidade na estrutura da rede. Na estrutura de rede social, ao invés de analisar comportamentos, atitudes e crenças individuais dos atores, analisa-se as relações entre atores em interação.

Para Ribault et al. (1995), a rede de empresas é um modo de grupabilidade destinada a favorecer a atividade de cada uma delas sem que estas tenham forçosamente laços financeiros entre si. As empresas em rede complementam-se umas às outras tanto em sua atividade produtiva, quanto mercadológica.

Id en line Revista de Psicologia. Ano 8, No. 22, Fevereiro/2014 - ISSN 1981-1179.

Edição eletrônica em http://idonline.emnuvens.com.br/id 
Em linhas gerais, características importantes e interessantes da estrutura em rede permitem o alcance do sucesso, de modo que, para um bom funcionamento dos relacionamentos, a comunicação e o intenso fluxo de informação são essenciais, sejam eles de caráter institucional, interpessoal ou interorganizacional.

\section{Conclusão}

As teorias de Heider e Lévi-Strauss sobre as relações interpessoais tem em comum o fato de serem teorias de relações entre atores e não entre seus atributos. Não é a informação, a riqueza ou até o status dos atores que explicam as situações em que se encontram, mas antes as relações que mantêm ou não uns com os outros. É neste ponto que as teorias estão estruturadas, por oposição às teorias que se baseiam nos determinantes da ação, no seu caráter, nas finalidades e nas crenças dos atores.

Ao se traduzir as teorias abordadas neste trabalho, podemos intuir que a cooperação interorganizacional pode proporcionar inúmeros benefícios, uma vez que atende as necessidades das empresas atuarem em grupo (redes).

Pode-se observar que existe uma tentativa de contextualizar a grupabilidade a partir da revisão teórico-metodológica das teorias que buscam explicar as relações interpessoais. Longe de se chegar a uma definição acabada a respeito da teoria das relações, o que se propõe é a reflexão a respeito da tensão cognitiva, atribuição causal ao equilíbrio, ao estruturalismo e as relações de parentesco.

Este trabalho foi uma tentativa de elucidar a maneira como as teorias das relações interpessoais interferiram no mecanismo das redes de relacionamento das empresas, seja por decisões grupais ou dissonantes. Podemos concluir que a reflexão do estruturalismo e o átomo do parentesco de Lévi-Strauss à luz da composição das relações de redes de empresas se delineiam em uma abordagem voltada para figura da relação, que é partidária da existência de regras estruturais e da cultura humana, destacando o papel de construção de pares de oposição e de organização do sentido, sugerindo que nesta analogia em estruturas que as organizações não sobrevivem individualmente.

Ao considerarmos a teoria da atribuição causal e o equilíbrio cognitivo de Heider (1970) podemos compreender com mais clareza a forma como as redes de empresas surgem e seu caráter de inter-relação, na busca de um equilíbrio e harmonia para se manterem e obterem lucros por meio do nicho em que está inserida.

Id en line Revista de Psicologia. Ano 8, No. 22, Fevereiro/2014 - ISSN 1981-1179. Edição eletrônica em http://idonline.emnuvens.com.br/id 


\section{Referências}

ALEJANDRO, V. A. O., e NORMAN, A. G. Manual introdutório à análise de redes sociais, 2006.

ÁVILA, L. A. O grupo do corpo e o corpo do grupo. Revista de Ciências Humanas, 2000, v.28 n.1, p. 101-106.

BRUSCO, S. The rules of the game in industrial districts. In: Grandori, A. (ed.) Interfirm networks: organization and industrial competitiveness. London: Routledge, 1999.

BURTY, R. S. The social structure of competition. In: Nohria, N., e Eccles, R. G. Networks and organizations: structure, form and action. Boston Harvard Business School, 1992.

CHAUí, M. de S. Cultura e democracia: o discurso competente e outras falas. São Paulo: Moderna, 1980.

D’AgOstine, F. Analíticos e continentais. São Leopoldo: Unisinos, 2002.

FERREIRA, M. C. A psicologia social contemporânea: principais tendências e perspectivas Nacionais e Internacionais. Psicologia: teoria e pesquisa, 2010, v.26(esp.), p. 51-64.

GRANOVETTER, M. S. The strength of weak ties. American Journal of Sociology, 1973, v. 6, p.1360-1380.

GUERRIERI, P., e PIETROBELLI, C. Industrial districts' evolution and technological regimes: Italy and Taiwan. Technovation, 2004, v.24,p. 899-914.

HEIDER, F. Psicologia das relações interpessoais. São Paulo: Pioneira, 1970.

HUTT, M. D., STANDORDT, E. R, WALKER, B. A., e REIGEN, P. H. Case study: defining the social network of a strategic alliance. Sloan Management Review, 2000, v.41, n.2, p. 51-62.

LEMIEUX, V., e OUIMET, M. Análise estrutural das redes sociais. Lisboa: Instituto Piaget, 2008. 
LEVI-STRAUSS, C. A noção de estrutura em etnologia; Raça e história; Totemismo hoje (2nd ed, Coleção Os Pensadores). São Paulo: Abril Cultural, 1980.

As estruturas elementares do parentesco (4nd ed). Rio de Janeiro: Vozes, 1976.

PAULUS, P. (1989). Psychology of group influence. Hillsdale: Erlbaum.

PELLÓN, E. G. Introducción a la antropología social y cultural. Cantabria: Univeridad Cantabria, 2010.

PROCOPIUCK, M., e FREY, K. Redes sociotécnicas de difusão de TIC's em porto Alegre e Curitiba. In: ENCONTRO DA ASSOCIAÇÂO NACIONAL DOS PROGRAMAS DE PÓSGRADUAÇÃO EM ADMINSITRAÇÃO, 31, 2007. Anais... Rio de Janeiro: ANPAD.

PUTNAM, R. D. Bowling alone. New York: Simon e Schuster, 2000.

RIBAUlt, J. M., MARTINET, B., \& LEBIDOIS, D. A. A Gestão das tecnologias. Lisboa: Dom Quixote, 1995.

SAN ROMÁN, T., e ECHAVARRÍA, A. G. Las relaciones de parentesco. Bellaterra: Universitat Autònoma de Barcelona, 1994.

SARTI, C. A. Parentesco e família. ComCiência. 2009. Retrieved 16 out de 2012 $<$ http://www.comciencia.br/comciencia/handler.php?section=8\&edicao=46\&id=552>.

SIMANKE, R. T. Metapsicologia lacaniana. Curitiba: UFPR, 2002.

Como citar este artigo (Formato ISO):

OLIVEIRA, N.; SILVA, M.L.; CASTRO, C.C. A Psicologia no mundo atAs contribuições de Heider e LéviStrauss para teoria da grupabilidade: uma reflexão à luz da estrutura das relações de redes de empresas. Id on Line Revista de Psicologia, Fevereiro de 2014, vol.8, n.22, p. 202-215. ISSN 1981-1189. 